\title{
METABOLITE PROFILING OF BILBERRIES (VACCINIUM MYRTILLUS L.)
}

\author{
(c) Martinussen Inger ${ }^{1}$, Rohloff Jens ${ }^{2}$, Jakkola Laura ${ }^{3}$, Trost Kajetan $^{4}$, \\ Junttila Olavi ${ }^{5}$, Häggman Hely ${ }^{3}$, Uleberg Eivind ${ }^{1}$
}

\author{
${ }^{1}$ Norwegian Institute for Agricultural and Environmental Research, Bioforsk Nord Holt, Box 2284, N-9269 Tromsø, Norway \\ ${ }^{2}$ The Plant Biocentre, Department of Biology, Norwegian University of Science and Technology (NTNU), N-7491 Trondheim, \\ Norway \\ ${ }^{3}$ Department of Biology, University of Oulu, POB 3000, FIN-90014 Oulu, Finland \\ ${ }^{4}$ University of Nova Gorica, Wine Research Centre, Vipavska 11c, SI-5270 Ajdovščina, Slovenia \\ 5 Institute of Biology, University of Tromsø, N-9037 Tromsø, Norway
}

The effects of climate on production and the quality of bilberries have been studied in a controlled phytotrone experiment using clonal material originating from Northern and Southern parts of Finland. In the experiment individual plants from two Northern clones and two Southern clones have been grown at $12^{\circ}$ and $18^{\circ} \mathrm{C}$. At each temperature 3 different light treatments have been tested; 1) $24 \mathrm{~h}$ natural light (long day), 2) $12 \mathrm{~h}$ natural light (short day) and 3) $24 \mathrm{~h}$ natural light with an addition of extra red light. All berries produced by each plant have been harvested at maturity and have been analyzed for several important quality parameters. The meta- bolic profiling results show that levels of flavonols (epicatechin and catechin), hydroxyl acids (chlorogenic acid, hydroxyl cinnamic acid), quinic acid and all analyzed carbohydrates (myo-inositol, fructose, glucose and sucrose) are highest at $12{ }^{\circ} \mathrm{C}$. On the contrary, total anthocyanins levels were highest at $18{ }^{\circ} \mathrm{C}$ and this was also reflected in the results on analysis of several anthocyanins derivates with the exception of Del 3-Ara that was significantly higher at $12^{\circ} \mathrm{C}$ than $18^{\circ} \mathrm{C}$. Northern clones had significantly higher levels of total anthocyanins, all measured anthocyanin derivates, total phenols, malic acid and sucrose than Southern clones.

\section{ANTIOXIDANT AND ANTIRADICAL CAPACITY OF PLANT EXTRACTS FROM ANGOLA}

\section{(C) Fernandes Nelson ${ }^{1}$, Mendonça António ${ }^{1}$, Mendonça Dina ${ }^{2}$}

${ }^{1}$ CICS-UBI - Centro de Investigação em Ciências da Saúde, Universidade da Beira Interior, Av. Infante D. Henrique, 6200506 Covilhã, Portugal

${ }^{2}$ Unidade de Materiais Têxteis e Papeleiros, Universidade da Beira Interior, Rua Marques Avilae Bolama, Covilhã, Portugal

Plant extracts have great potential as a source of new medicines to many diseases such as Alzheimer disease or cancer (1). Oxidative stress takes part in the pathogenesis of these and other diseases. Phenolic compounds derived from secondary metabolism of plants, showed to provide a defence against free radicals. The antioxidant and anti-radical capacity from extracts (aqueous, methanol, chloroform, ethyl acetate and n-hexane) of Phragmanthera glaucocarpa (Peyr.) Balle (Fam. Loranthaceae) an Piliostigma thonningii (Shum.) Milne-Redh. (Fam. Fabaceae) were evaluated by DPPH and ABTS methods. DPPH inhibition ( $\%$ ) by the ethyl acetate $P$. glaucocarpa extract was $18.9 \% \pm 0.5 \%$ whereas with a Trolox solution with the same concentration
(0.05 mg/mL) $65.5 \% \pm 0.5 \%$ was obtained. Identical result was obtained for ABTS radical scavenging when ABTS radical was inhibited by Trolox $(10.2 \pm 0.1 \%)$ and by $P$. glaucocarpa ethyl acetate extract $(2.8 \% \pm 0.1 \%)$. Total phenolics were evaluated by the Folin-Ciocalteau method with the highest concentration obtained in the $P$. glaucocarpa ethyl acetate extract (174.0 $\pm 0.1 \mathrm{mg}$ of gallic acid equivalent (GAE)/g of extract) followed by $P$. thonningii ethyl acetate extract $(107.6 \pm 0.1 \mathrm{mg}$ of gallic acid equivalent (GAE)/g of extract). $P$. glaucocarpa can be a source of phenolics and other promising natural coumpouds.

Reference: (1) Kumaran, A.; Karunakaran, R.J. Food Chemistry, 97 (2006): 109-114. 